\title{
Nanoprecipitation of polymeric nanoparticle micelles based on 2-methacryloyloxyethyl phosphorylcholine (MPC) with 2-(diisopropylamino)ethyl methacrylate (DPA), for intracellular delivery applications
}

\author{
Jonathan P. Salvage ${ }^{1} \cdot$ Christopher Thom $^{1} \cdot$ Andrew L. Lewis $^{2} \cdot$ Gary J. Phillips $^{1}$ • \\ Andrew W. Lloyd ${ }^{1}$
}

Received: 8 January 2015/ Accepted: 1 March 2015/Published online: 14 March 2015

(c) The Author(s) 2015. This article is published with open access at Springerlink.com

\begin{abstract}
Biodistribution of nanoparticle-based intracellular delivery systems is mediated primarily by particle size and physicochemical properties. As such, overcoming the rapid removal of these by the reticuloendothelial system remains a significant challenge. To date, a number of copolymer nanoparticle systems based on 2-methacryloyloxyethyl phosphorylcholine (MPC) with 2-(diisopropylamino)ethyl methacrylate (DPA), displaying biomimetic and $\mathrm{pH}$ responsive properties, have been published, however these have been predominately polymersome based, whilst micelle systems have remained relatively unexplored. This study utilised nanoprecipitation to investigate the effects of solvent and buffer choice upon micelle size and polydispersity, and found using methanol produced monodisperse micelles of circa $70 \mathrm{~nm}$ diameter, whilst ethanol produced polydisperse systems with nanoparticles of circa $128 \mathrm{~nm}$ diameter. The choice of aqueous buffer, dialysis of the systems, extended storage, and exposure to a wide temperature range $\left(5-70{ }^{\circ} \mathrm{C}\right)$ had no significant effect on micelle size, and the systems were highly resistant to dilution, indicating excellent colloidal stability. Optimisation of the nanoprecipitation process, post precipitation, was investigated, and model drugs successfully loaded whilst maintaining system stability. Subsequent in vitro studies suggested that the micelles were of negligible
\end{abstract}

Jonathan P. Salvage

J.P.Salvage@brighton.ac.uk

1 School of Pharmacy and Biomolecular Sciences, University of Brighton, Huxley Building, Lewes Road, Brighton BN2 4GJ, UK

2 Biocompatibles UK Ltd, a BTG International plc Group Company, Innovation Group, Lakeview, Riverside Way, Watchmoor Park, Camberley GU15 3YL, UK cellular toxicity, and an apparent cellular uptake was observed via confocal laser scanning microscopy. This paper presents the first report of an optimised nanoprecipitation methodology for the formation of MPC-DPA nanoparticle micelles, and in doing so achieved monodisperse systems with the size and physicochemical characteristics seen as desirable for long circulating therapeutic delivery vehicles.

\section{Introduction}

The research and development of systemically administrable nanoparticulate-based intracellular delivery systems (NIDS) is driven by the need to overcome a number of key challenges. The hurdles faced by NIDS include dilution induced micelle dissociation, resulting in dose dumping, and the more problematic rapid removal from the circulatory blood stream by the reticuloendothelial system (RES), mediated by particle size and physichochemical properties [1]. Whilst polymeric micelle systems have been shown to be able to withstand dilution to low concentrations, and thus offer the potential for systemic stability [2,3], overcoming the RES remains a challenge. The main organs of the RES, the liver, spleen, and bone marrow, facilitate the removal of conventional NIDS within minutes of intravenous injection [4].

Two major factors are involved in this rapid removal, (i) opsonisation of the particle, and (ii) particle size. Opsonisation of NIDS occurs rapidly after injection [5] resulting in a surface layer of proteins on the NIDS which promote recognition and phagocytosis by the macrophages of the RES. Particle size of the NIDS can modulate both mechanical filtration and RES-based macrophage removal. Micron size range particles face capillary filtration in the lungs and spleen [6,7], with particles of $1-2 \mu \mathrm{m}$ having 
been shown to induce maximum phagocytosis [8]. Therefore a sub-micron particle size is considered desirable for a long circulating NIDS. However particles above $200 \mathrm{~nm}$ are subject to mechanical filtration by the spleen [9], whilst those below $50 \mathrm{~nm}$ may be lost through the fenestrae that occur throughout the capillary network of the liver, spleen, and bone marrow [10,11]. Thus the range of particle sizes from 50 to $200 \mathrm{~nm}$ in diameter appears to offer the prospect of resistance to RES clearance. However, it has also been suggested that the use of protective surface coating technologies to extend nanoparticle circulatory times is less effective for particles with diameters greater than $150 \mathrm{~nm}$ [9], are more effective for particles within a narrower 60 to $100 \mathrm{~nm}$ size range [12]. When a NIDS possesses long circulating properties, tumour targeting can be achieved via the enhanced permeation and retention (EPR) effect, which will result in the passive accumulation of the NIDS at the tumour site via the leaky vasculature [13]. The long circulating properties are desirable as it has been hypothesised that a minimum of six hours are required for there to be effective EPR accumulation [14].

A number of successful biomedical materials have been successfully developed utilising phosphorylcholine (PC) [15] which possess biomimetic biocompatibility achieved by mimicking the surface of natural phospholipid membrane bilayers [16]. This could, in principle, reduce the protein adsorption and cell activation of NIDS containing PC, and therefore avoid macrophage-mediated RES removal.

Since the early reports of PC containing MPC-DPA nanoparticle systems $[17,18]$, there has been significant progress on the development of these in the form of polymeric vesicles, akin to liposomes, known as polymersomes [19, 20], whereas research into their further development as micelle-based NIDS has been more limited. Nevertheless, progress has been made with regard to demonstrating the continued potential for MPC-DPA based micelles to be effective NIDS [21, 22]. As such, this paper reports on the development of $\mathrm{MPC}_{100}-\mathrm{DPA}_{100}$ based micelle systems, which we have previously demonstrated possess some of the key attributes desirable in a NIDS: including drug analogue loading and release, $\mathrm{pH}$ responsiveness, dilution stability, and low cellular toxicity; but which were found to be below $50 \mathrm{~nm}$ in diameter, and of a polydisperse nature, having been formed by via a $\mathrm{pH}$ titration method [17]. Herein this paper reports the novel development and optimisation of a rapid and straightforward nanoprecipitation based method to achieve reproducible production of monodisperse MPC-DPA micelles. In doing so, this study investigated the effects of solvent and buffer choice, hydrophobic model drug loading, system temperature, and polymer concentration on the particle dynamics of the polymeric micelles formed, and is to the best of our knowledge the first report of this $\mathrm{MPC}_{100}$ $\mathrm{DPA}_{100}$ nanoprecipitated micelle system.

\section{Materials and methods}

\section{1 $\mathrm{MPC}_{100}-\mathrm{DPA}_{100}$ diblock copolymer}

The 100-100 diblock length copolymer, comprised of 2-methacryloyloxyethyl phosphorylcholine (MPC) with 2-(diisopropylamino)ethyl methacrylate (DPA), was supplied by Prof Steven Armes (University of Sheffield, UK), having been synthesised via atom transfer radical polymerisation (ATRP), and characterised with nuclear magnetic resonance (NMR) and gel permeation chromatography (GPC), as detailed previously $[17,18]$, where ${ }^{1} \mathrm{H}$ NMR and GPC indicated the block copolymer was well defined with $\mathrm{Mn}$ and polydispersity values of 51,000 and 1.27 respectively.

\subsection{Preparation of polymeric micelle systems via nanoprecipitation}

\subsubsection{Solvent ratio, time, and dialysis effect}

Solutions of the $\mathrm{MPC}_{100}-\mathrm{DPA}_{100}$ copolymer $\left(40 \mathrm{mg} \mathrm{ml}^{-1}\right)$ were prepared in methanol $(\mathrm{MeOH})$ (Fisher, UK) and ethanol (EtOH) (Fisher, UK), and $\mathrm{MeOH}: \mathrm{EtOH}$ volume combination ratios of $3: 1,1: 1$, and 1:3. Aliquots $(100 \mu \mathrm{l})$ of these were added drop-wise, using a micropipette, to $9.9 \mathrm{ml}$ of phosphate buffer saline (PBS) (Oxoid, UK), $\mathrm{pH}$ 7.4 , stirring with a $1 \mathrm{~cm}$ magnetic flea $(1,250 \mathrm{rpm}, 2 \mathrm{~min})$ and subsequently bath sonicated for $5 \mathrm{~min}$. Final copolymer concentration was $0.4 \mathrm{mg} \mathrm{ml}^{-1}$. The systems were examined at time zero $(\mathrm{t}=0)$ and at 6 weeks post micelle formation $(\mathrm{t}=6)$, (room temperature storage), and also pre and post 1 week of dialysis, ( $8 \mathrm{kDa}$ molecular weight cutoff) (BioDesign, USA), in PBS (pH 7.4) with daily PBS changes, using photon correlation spectroscopy (PCS).

\subsubsection{Solvent, buffer, hydrophobic loading, dilution, and temperature effect}

Solutions of the $\mathrm{MPC}_{100}-\mathrm{DPA}_{100}$ copolymer $\left(40 \mathrm{mg} \mathrm{ml}^{-1}\right)$ were prepared in $\mathrm{MeOH}$ and $\mathrm{EtOH}$ with and without a model hydrophobic compound Orange OT dye (OOT) (Sigma, UK), at a polymer to OOT mol ratio of 2:1. Aliquots $(100 \mu \mathrm{l})$ of these were added drop-wise to $9.9 \mathrm{ml}$ of PBS, pH 7.4, or MCIlvaines buffer (McB) (in-house), $\mathrm{pH}$ 7.4 , stirring with a $1 \mathrm{~cm}$ magnetic flea $(1,250 \mathrm{rpm}, 2 \mathrm{~min})$ and subsequently bath sonicated for $5 \mathrm{~min}$. The systems were examined for dilution and temperature stability using PCS. 


\subsubsection{Stirring, sonication, and filtration effect}

Solutions of the $\mathrm{MPC}_{100}-\mathrm{DPA}_{100}$ copolymer $\left(40 \mathrm{mg} \mathrm{ml}^{-1}\right)$ were prepared in $\mathrm{MeOH}$, and aliquots $(100 \mu \mathrm{l})$ of these were added drop-wise to $9.9 \mathrm{ml}$ of PBS, $\mathrm{pH} 7.4$, under the following preparation conditions: (A) no stirring, no sonication, no filtration, (B) no stirring, no sonication, $0.22 \mu \mathrm{m}$ pore size syringe filtered (Millipore), (C) stirring (1,250 rpm, $2 \mathrm{~min})$, sonication $(5 \mathrm{~min})$, no filtration, (D) stirring $(1,250 \mathrm{rpm}, 2 \mathrm{~min})$, sonication $(5 \mathrm{~min})$, $0.22 \mu \mathrm{m}$ pore size syringe filtered.

\subsubsection{Loading ratio of fluorescent probe}

Solutions of the $\mathrm{MPC}_{100}-\mathrm{DPA}_{100}$ copolymer $\left(40 \mathrm{mg} \mathrm{ml}^{-1}\right)$ were prepared in $\mathrm{MeOH}$ with the fluorescent probe Nile Red (NR) (Sigma, UK) at polymer to NR weight ratios of: (A) 10:0.1, (B) 10:0.5, (C) 10:0.75, (D) 10:1. Aliquots $(100 \mu \mathrm{l})$ of these were added drop-wise to $9.9 \mathrm{ml}$ of PBS, $\mathrm{pH} 7.4$, with no stirring or sonication, and the resultant samples $0.22 \mu \mathrm{m}$ pore size syringe filtered.

\subsection{Particle size characterisation}

Particle size characterisation of the prepared micelle systems was undertaken using photon correlation spectroscopy (PCS), atomic force microscopy (AFM), and transmission electron microscopy (TEM).

\subsubsection{Photon correlation spectroscopy}

The PCS instrument employed in this study was a Malvern Zetasizer $3000 \mathrm{HS}$, equipped with a $10 \mathrm{~mW} \mathrm{He}-\mathrm{Ne}$ laser operating at a wavelength of $633 \mathrm{~nm}$, together with a high sensitivity avalanche photodiode detector (APD) at $90^{\circ}$ collection angle. Sample temperature was maintained during PCS measurement by a Peltier thermal cuvette mounting stage. Each PCS size measurement had a duration of $600 \mathrm{~s}$, consisting of 30 analyses by the Malvern PCS software, of fluctuations in the scattered light data collected by the APD, in order to determine the intensity based hydrodynamic diameter $\left(D_{h}\right)$ and system polydispersity $(\mathrm{Pd})$. The $\mathrm{D}_{\mathrm{h}}$ being calculated by the Stokes-Einstein equation $\left(D_{h}=k T /\right.$ $3 \pi \eta d$ ), where $D_{h}=$ hydrodynamic diameter, $d=$ diffusion coefficient, $\mathrm{k}=$ Boltzmann's constant, $\mathrm{T}=$ absolute temperature, and $\eta=$ viscosity.

The solvent ratio, time, and dialysis effect systems (Sect. 2.2.1) were examined using PCS, at $25^{\circ} \mathrm{C}$, to determine the $\mathrm{D}_{\mathrm{h}}$ and system Pd at time zero $(\mathrm{t}=0)$ and at 6 weeks post micelle formation $(t=6)$, and also pre and post 1 week of dialysis (8 $\mathrm{kDa}$ cut-off) in PBS (pH 7.4) following daily PBS changes. Samples were filtered with
$0.2 \mu \mathrm{m}$ pore size syringe filters immediately prior to measurement to ensure sample quality.

The solvent, buffer, hydrophobic compound loading, dilution, and temperature effects on the systems (Sect. 2.2.2) were examined using PCS, at $25{ }^{\circ} \mathrm{C}$, to determine $D_{h}$ and system $P d$ in response to solvent and buffer variation, with and without OOT loaded in the systems. The dilution stability of the PBS systems was examined at $25{ }^{\circ} \mathrm{C}$, by measuring signal intensity (KCps), $\mathrm{D}_{\mathrm{h}}$ and $\mathrm{Pd}$ in response to halving dilutions of the micelle solutions made using pre-filtered $(0.2 \mu \mathrm{m})$ PBS $(\mathrm{pH} 7.4)$. The diluted samples were filtered with $0.2 \mu \mathrm{m}$ pore size syringe filters immediately prior to measurement, as before. The thermal stability of the PBS systems was examined by measuring the $D_{h}$ and Pd across the temperatures range of $5-70{ }^{\circ} \mathrm{C}$, at $5{ }^{\circ} \mathrm{C}$ intervals. Samples were equilibrated for $20 \mathrm{~min}$ after each $5{ }^{\circ} \mathrm{C}$ temperature change before PCS measurement commenced, to ensure only Brownian motion was measured. The stirring, sonication and filtration effects on the systems (Sect. 2.2.3) were examined using PCS, at $25^{\circ} \mathrm{C}$, to determine $D_{h}$ and system $\mathrm{Pd}$, without further sample filtration.

The effects of loading ratio of a fluorescent probe (Sect. 2.2.4) were examined using PCS, at $25^{\circ} \mathrm{C}$, to determine $\mathrm{D}_{\mathrm{h}}$ and system Pd. Samples were filtered through a $0.2 \mu \mathrm{m}$ pore size syringe filter immediately prior to measurement. Post instrument loading, the samples were allowed to equilibrate for $1 \mathrm{~min}$ per degree of temperature change, plus $5 \mathrm{~min}$, from the room temperature before PCS measurement commenced at $25^{\circ} \mathrm{C}$.

\subsubsection{Atomic force microscopy}

$\mathrm{MPC}_{100}-\mathrm{DPA}_{100}$ dissolved in $\mathrm{MeOH}\left(40 \mathrm{mg} \mathrm{ml}^{-1}\right)$ was added drop wise to $\mathrm{pH}$ adjusted deionised water (D.I.) under the same conditions used to prepare the PBS based system in Sect. 2.2.2. The micelle solution was then applied drop-wise to a mica wafer (in house) and air dried. The AFM imaging was carried out using a VEECO Nanoscope 111A atomic force microscope in Tapping Mode $^{\mathrm{TM}}$, operating at a scan rate of $0.5 \mathrm{~Hz}$, a scan size of $3 \mu \mathrm{m}$, and using Point probes type PPP-NCH-W tips (Nanosensors).

\subsubsection{Transmission electron microscopy}

The $\mathrm{MPC}_{100}-\mathrm{DPA}_{100}$ micelle solution, as described in Sect. 2.3.2, was mixed with $2 \%$ phosphotungstic acid $(\mathrm{pH}$ 7.4) (Sigma, UK) at a 1:1 volume ratio as a negative stain, and then applied drop-wise to Formvar coated copper grids (Agar Scientific) and allowed to air dry. The prepared grids were imaged using a Phillips CM10 TEM at an accelerating voltage of $80 \mathrm{kV}$. Deionised water (pH adjusted) was 
employed for the AFM and TEM samples to minimise presence of salts upon drying.

\subsection{Cell study}

\subsubsection{In-vitro cell cytotoxicity study}

The cytotoxicity assay used was based on published methods [23], and had been previously employed to successfully test MPC-DPA micelle systems [17]. $\mathrm{MPC}_{100^{-}}$ $\mathrm{DPA}_{100}(\mathrm{MeOH}-\mathrm{PBS})$ ( $\mathrm{pH}$ 7.4) based micelle systems were prepared at $0.4 \mathrm{mg} \mathrm{ml}^{-1}$, as per Sect. 2.2.2. Hamster lung V79 fibroblast cells (Japanese Cancer Research Resources Bank (JCRB), Japan) were maintained in Dulbecco's Modified Essential Medium (DMEM) (PAA, UK) supplemented with $10 \%$ foetal calf serum (FCS) (PAA, UK) and $1 \%$ penicillin and streptomycin (P\&S) (PAA Labs). 24 well plates (Nunc, UK) were seeded with 100 V79 cells per well in $500 \mu \mathrm{l}$ of DMEM (10\% FCS, $1 \%$ $\mathrm{P} \& \mathrm{~S}$ ) and incubated at $37{ }^{\circ} \mathrm{C}$, in $5 \% \mathrm{CO}_{2}$ for $24 \mathrm{~h}$ to facilitate cell attachment. The $0.4 \mathrm{mg} \mathrm{ml}^{-1}$ micelle solutions were filter sterilised $(0.22 \mu \mathrm{m})$ before preparing a series of 10-fold serial dilutions in DMEM (2.5\% FCS, $1 \% \mathrm{P} \& \mathrm{~S}$ ) to provide polymer concentrations of $200,20,2$, 0.2 and $0.02 \mu \mathrm{g} \mathrm{ml}^{-1}$. After the $24 \mathrm{~h}$ cell attachment period, the supplemented DMEM was removed from the cells and replaced with $500 \mu \mathrm{l}$ of the prepared dilutions of the polymer solutions, pre-warmed to $37^{\circ} \mathrm{C}$ (four replicate wells per test concentration). Control samples of PBS and $\mathrm{MeOH}$ at the concentrations used for the polymer samples were also prepared and tested. A blank control plate containing cells in fresh DMEM supplemented with $2.5 \%$ FCS and $1 \%$ P\&S was used to provide the $100 \%$ survival figure. The plates were incubated at $37{ }^{\circ} \mathrm{C}$ in $5 \% \mathrm{CO}_{2}$ for 5 days to allow cell colonies to grow. The FCS concentration was reduced to $2.5 \%$ from $10 \%$ to attenuate cell growth. After 5 days the resultant colonies were fixed with gluteraldehyde (Sigma, UK) and stained with $10 \% \mathrm{v} / \mathrm{v}$ Giemsa stain (Sigma, UK). The numbers of colonies in each well were counted and the percentage of colony reduction compared to the control wells was calculated for each dilution of each sample type.

\subsubsection{Cellular uptake of dye loaded micelles}

V79 cells were maintained in DMEM supplemented with $10 \% \mathrm{FCS}$ and $1 \% \mathrm{P} \& \mathrm{~S}$, and seeded into 24 well plates at 1,000 cells per well in $500 \mu \mathrm{l}$ of DMEM (2.5\% FCS, $1 \%$ $\mathrm{P} \& S$ ) and incubated at $37{ }^{\circ} \mathrm{C}$, in $5 \% \mathrm{CO}_{2}$ for $48 \mathrm{~h}$. MPC $_{100}-\mathrm{DPA}_{100}(\mathrm{MeOH}-\mathrm{PBS})$ micelle systems loaded with NR (10:0.5 w/w ratio) were prepared as per Sect. 2.2.4, substituting the PBS with DMEM (2.5\% FCS, $1 \% \mathrm{P} \& \mathrm{~S})$ in order to produce a final polymer concentration of $200 \mu \mathrm{g} \mathrm{ml}^{-1}$. The prepared polymer micelle solution, with NR, in DMEM (2.5 \% FCS, $1 \% \mathrm{P} \& \mathrm{~S})$ was filter sterilised $(0.22 \mu \mathrm{m})$, and used to replace the DMEM on the incubated cells. The cells were then incubated for a further $48 \mathrm{~h}$ at $37{ }^{\circ} \mathrm{C}$, in $5 \% \mathrm{CO}_{2}$. At the $96 \mathrm{~h}$ time point, fresh DMEM was used to replace the test samples in the wells, having washed the wells twice with $1 \mathrm{ml}$ sterile PBS beforehand. The cells were then observed using a Leica SP5 confocal laser scanning microscopy (CLSM) equipped with an argon laser, using an excitation wavelength of $514 \mathrm{~nm}$, and an emission collection wavelength band of 550-617 nm.

\section{Results}

\subsection{Solvent ratio, time, and dialysis effect}

A range of $\mathrm{MeOH}$ and $\mathrm{EtOH}$ solvent v/v ratio combinations were used to prepare micelle systems of $\mathrm{MPC}_{100^{-}}$ $\mathrm{DPA}_{100}$ in PBS. The PCS data $\left(\mathrm{D}_{\mathrm{h}}\right.$ and Pd) presented in Fig. 1 indicated that for systems prepared from $100 \%$ $\mathrm{MeOH}$, and $\mathrm{MeOH}: \mathrm{EtOH}$ ratios of 3:1, and 1:1 the mean $\mathrm{D}_{\mathrm{h}}$ was circa $70 \mathrm{~nm}$. When the EtOH ratio was increased to 3:1 the $\mathrm{D}_{\mathrm{h}}$ increased to a mean of circa $82 \mathrm{~nm}$, and the $100 \% \mathrm{EtOH}$ system increased the mean $\mathrm{D}_{\mathrm{h}}$ to circa $128 \mathrm{~nm}$. The Pd of the $100 \% \mathrm{MeOH}$ derived system was below 0.1 , indicating a monodisperse population, however as the EtOH ratio increased so did the Pd of the systems, going beyond 0.2 in some cases, indicating the development of polydisperse broader particle size range systems. Comparison of the $\mathrm{t}=0$ with 6 data presented in Fig. 1 indicated that the systems were stable over a 6 week storage period, with the $\mathrm{D}_{\mathrm{h}}$ and $\mathrm{Pd}$ of the systems remaining relatively consistent for that period. The pre and

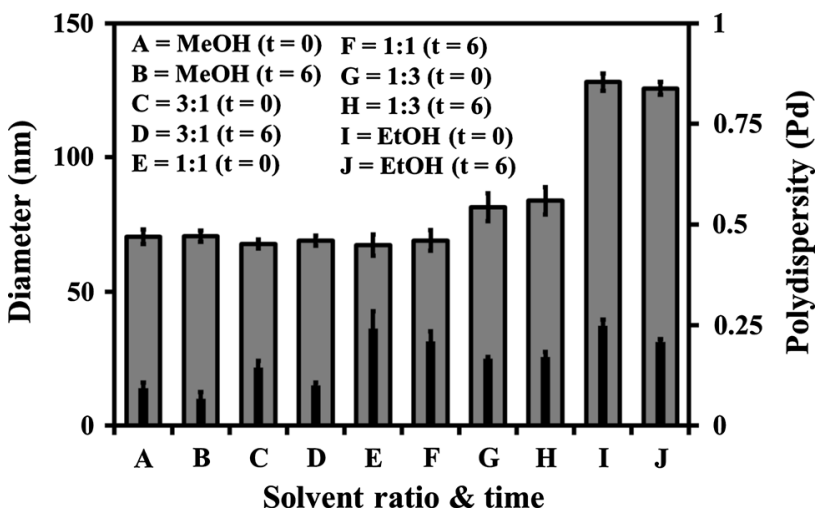

Fig. 1 Particle diameter (outer bar) and polydispersity (inner bar), measured with PCS $\left(25^{\circ} \mathrm{C}\right)$, of $\mathrm{MPC}_{100}-\mathrm{DPA}_{100}$ micelles, formed via nanoprecipitation from solvent $(\mathrm{MeOH}, \mathrm{EtOH}$, and $\mathrm{v} / \mathrm{v}$ combinations of $)$, in PBS ( $\mathrm{pH} 7.4)$, at time zero $(\mathrm{t}=0)$ and 6 weeks post formation $(\mathrm{t}=6)($ Mean $\pm \mathrm{SD}, \mathrm{n}=6)$ 
post dialysis data displayed in Fig. 2 agreed with the data in Fig. 1, and indicated that dialysis of the systems had little discernable effect on their average $\mathrm{D}_{\mathrm{h}}$ and $\mathrm{Pd}$.

\subsection{Solvent, buffer, hydrophobic loading, dilution, and temperature effect}

$\mathrm{MPC}_{100}-\mathrm{DPA}_{100}$ micelle systems were prepared in either $\mathrm{McB}$ ( $\mathrm{pH}$ 7.4) or PBS (pH 7.4) via nanoprecipitation using $\mathrm{EtOH}$ and $\mathrm{MeOH}$, with and without OOT, as displayed in Fig. 3. The systems prepared using EtOH, both with and without OOT, and in PBS and McB, produced micelle systems with a mean $\mathrm{D}_{\mathrm{h}}$ of circa $128 \mathrm{~nm}$, and high $\mathrm{Pd}$ values exceeding 0.2 , indicating the presence of polydisperse systems. The $\mathrm{MeOH}$ prepared systems, both with and without OOT, in PBS and McB produced micelle systems with mean $D_{h}$ values of circa 70 and $74 \mathrm{~nm}$, respectively, with low, monodisperse, Pd values below 0.1 for both systems. Thus the data in Fig. 3 indicated that the choice of buffer or loading with a hydrophobic compound (OOT) did not significantly alter the mean $\mathrm{D}_{\mathrm{h}}$ and $\mathrm{Pd}$ of the either the $\mathrm{EtOH}$ or $\mathrm{MeOH}$ prepared systems, with only minor $\mathrm{D}_{\mathrm{h}}$ changes observed when the buffer was switched for the $\mathrm{MeOH}$ systems.

The PBS based systems were further investigated, as displayed in Fig. 4(a-d) examining dilution stability of the micelles, with regard to the $\mathrm{D}_{\mathrm{h}}$ and PCS signal intensity. The EtOH-PBS systems, without (a) and with (b) OOT loaded demonstrated good resistance to micelle dissociation as the polymer concentration was halved with each dilution point, resulting in a steady decrease in signal intensity. The MeOH-PBS systems, without (c) and with (d) OOT loaded also displayed resistance to dilution induced micelle dissociation, as was evident by measureable

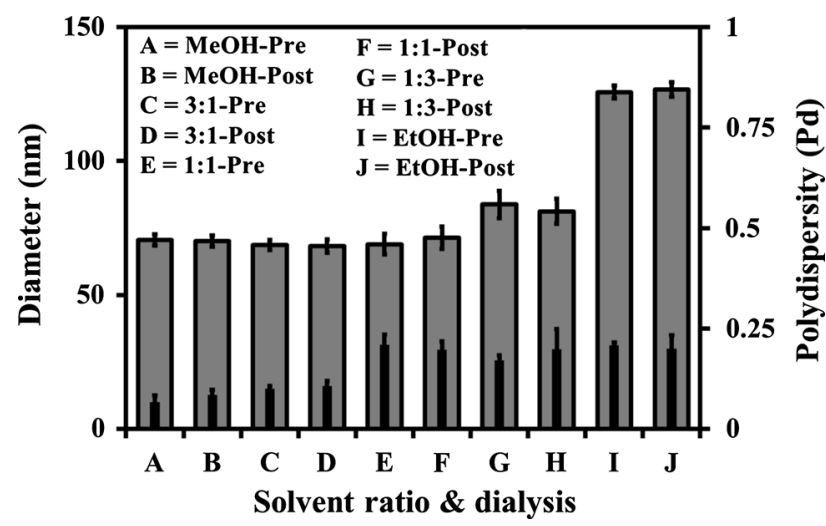

Fig. 2 Particle diameter (outer bar) and polydispersity (inner bar), measured with PCS $\left(25^{\circ} \mathrm{C}\right)$, of $\mathrm{MPC}_{100}-\mathrm{DPA}_{100}$ micelles, formed via nanoprecipitation from solvent $(\mathrm{MeOH}, \mathrm{EtOH}$, and v/v combinations of), in PBS ( $\mathrm{pH} 7.4$ ), pre and post dialysis (Mean $\pm \mathrm{SD}, \mathrm{n}=6$ )

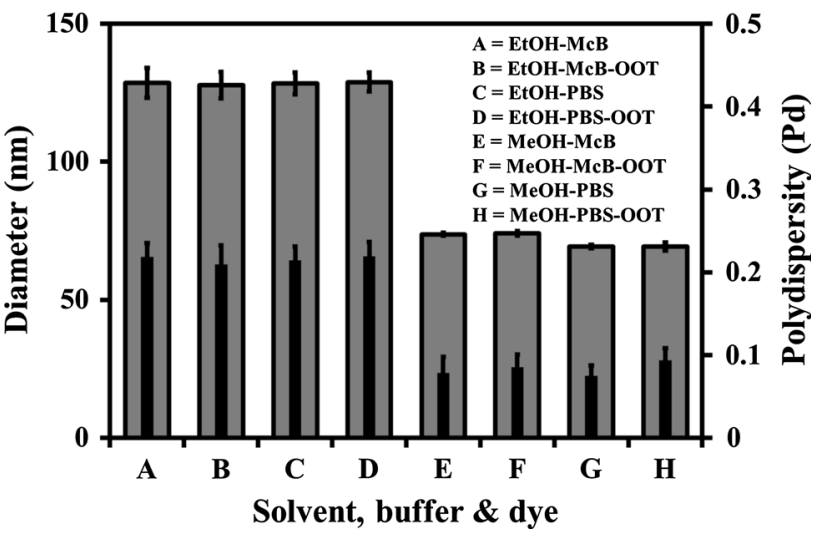

Fig. 3 Particle diameter (outer bar) and polydispersity (inner bar), measured with PCS $\left(25^{\circ} \mathrm{C}\right)$, of $\mathrm{MPC}_{100}-\mathrm{DPA}_{100}$ micelles, formed via nanoprecipitation from solvent $(\mathrm{MeOH}$ or $\mathrm{EtOH})$, in $\mathrm{McB}(\mathrm{pH}$ 7.4) and PBS (pH 7.4), with and without OOT entrapped (Mean \pm SD, $\mathrm{n}=6)$

particles down to the limit of detection for the PCS instrument, circa 5 KCps.

For the EtOH-PBS systems, particles were detectable down to a concentration of $0.0125 \mu \mathrm{M}$ (Fig. 4a, b), with an accompanying gradual reduction in the KCps signal intensity indicating that there were no sharp changes in mean particle size, which would have been seen upon a micelle to unimer shift, thus suggesting the persistent presence of micelles. The $\mathrm{MeOH}-\mathrm{PBS}$ based systems were measurable down to $0.0625 \mu \mathrm{M}$, and also displayed a gradual reduction on signal intensity associated with particle stability.

The systems were assessed for their temperature stability, with regard to $D_{h}$, across the temperature range of $5-70{ }^{\circ} \mathrm{C}$, as shown in Fig. 5. The EtOH-PBS systems, with and without OOT, remained stable throughout the temperature, with only a minor reduction in $\mathrm{D}_{\mathrm{h}}$ at the highest temperature of $70^{\circ} \mathrm{C}$, with average $\mathrm{D}_{\mathrm{h}}$ otherwise remaining circa $128 \mathrm{~nm}$ for the systems. The MeOH-PBS system, with and without OOT, also remained stable over the tested temperature range, with average $D_{h}$ of circa $70 \mathrm{~nm}$.

\subsection{Atomic force microscopy (AFM) and Transmission electron microscopy (TEM)}

AFM and TEM imaging was undertaken to further explore the size and morphology of the $\mathrm{MPC}_{100}-\mathrm{DPA}_{100} \mathrm{MeOH}$ system. AFM imaging revealed a uniform population of nanoparticles with a spherical morphology, seen as light particles against a darker background in Fig. 6. TEM imaging also indicated the presence of spherical particles, seen as light against the dark background in Fig. 7. The particle size indicated by AFM and TEM was circa 50-80 nm. 

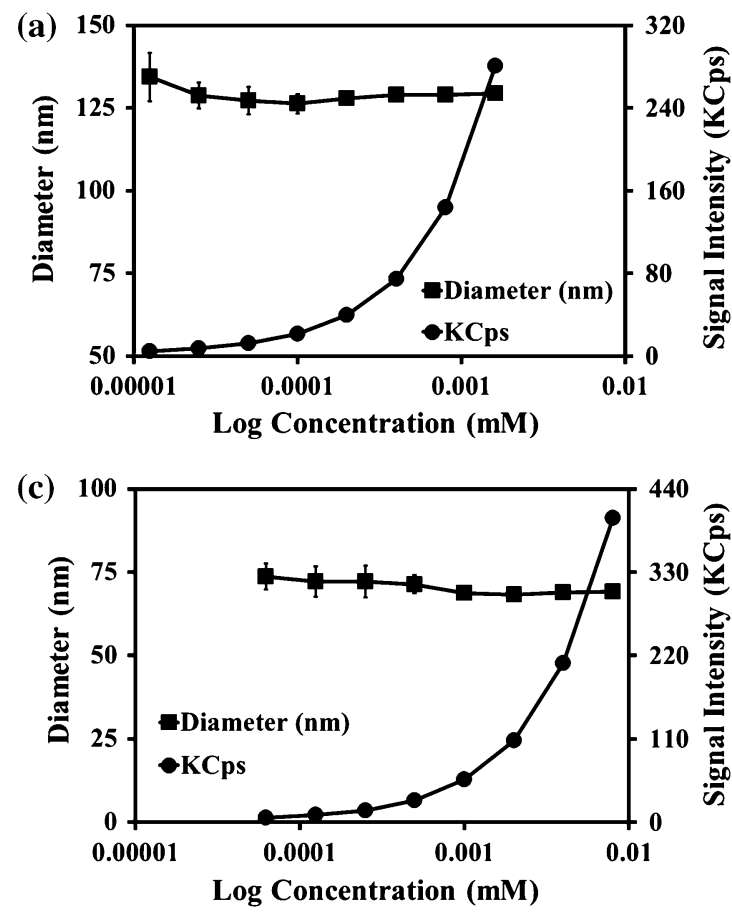

Fig. 4 Particle diameter and signal intensity (KCps), in response to dilution, of $\mathrm{MPC}_{100}-\mathrm{DPA}_{100}$ micelles measured with PCS $\left(25^{\circ} \mathrm{C}\right)$, formed via nanoprecipitation from solvent into buffer. a Ethanol-

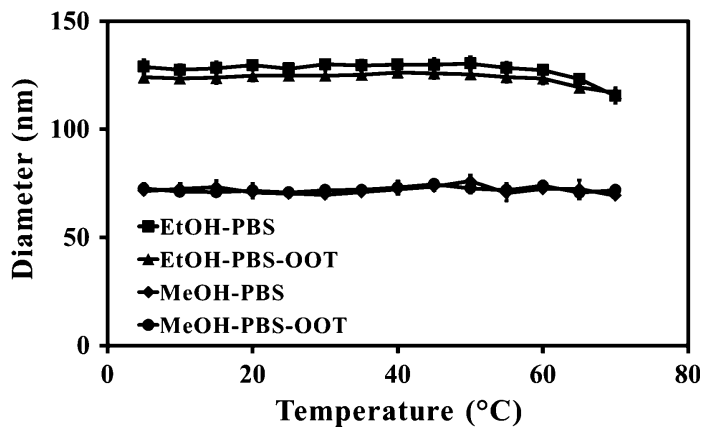

Fig. 5 Particle diameter in response to temperature measured with PCS $\left(5-70{ }^{\circ} \mathrm{C}\right)$, of $\mathrm{MPC}_{100}-\mathrm{DPA}_{100}$ micelles, formed via nanoprecipitation from solvent (MeOH or EtOH), in PBS (pH 7.4), with and without OOT entrapped (Mean $\pm \mathrm{SD}, \mathrm{n}=6$ )

\subsection{Stirring, sonication, and filtration effect}

To further optimise the preparation process the effects of stirring, sonication, and filtration upon $\mathrm{D}_{\mathrm{h}}$ and $\mathrm{Pd}$ of the $\mathrm{MeOH}-\mathrm{PBS}$ based system was examined. The results displayed in Fig. 8 show that the control samples (A), prepared using no stirring, sonication, or filtration during or after nanoprecipitation resulted in systems with average a $\mathrm{D}_{\mathrm{h}}$ of circa $113 \mathrm{~nm}$, and high mean Pd value of circa 0.6, suggesting the presence of a polydisperse system with larger, less well ordered, particle sizes. However, the samples prepared using filtration alone (B), stirring and
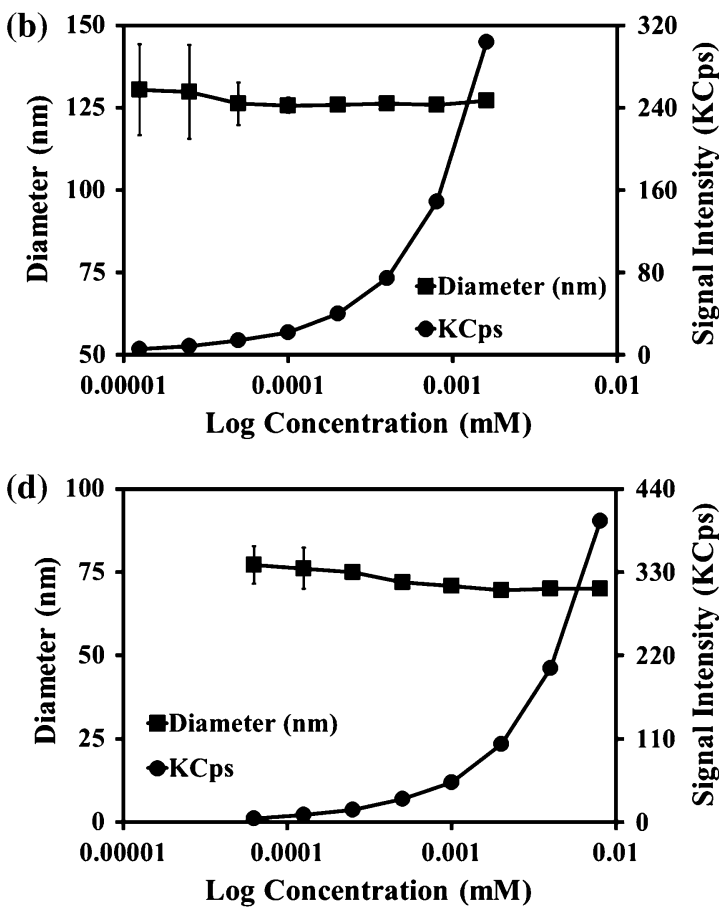

PBS, b ethanol-PBS-OOT, $\mathbf{c}$ methanol-PBS, $\mathbf{d}$ methanol-PBS-OOT $($ Mean $\pm \mathrm{SD}, \mathrm{n}=6)$

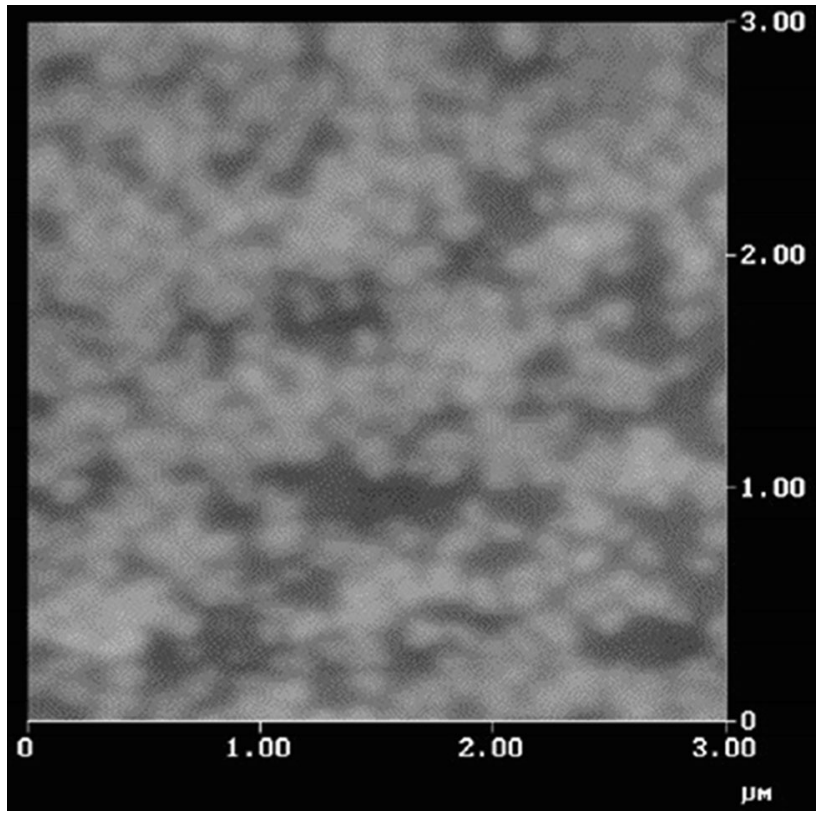

Fig. 6 AFM Tapping Mode ${ }^{\mathrm{TM}}$ image of $\mathrm{MPC}_{100}-\mathrm{DPA}_{100}$ nanoparticle micelles displaying diameters in the order of $60-70 \mathrm{~nm}$

sonication with no filtration (C), and stirring, sonication, and filtration combined (D), all resulted in systems with average $D_{h}$ values circa $70 \mathrm{~nm}$ and low Pd values. The results indicated that it was only necessary to filter 


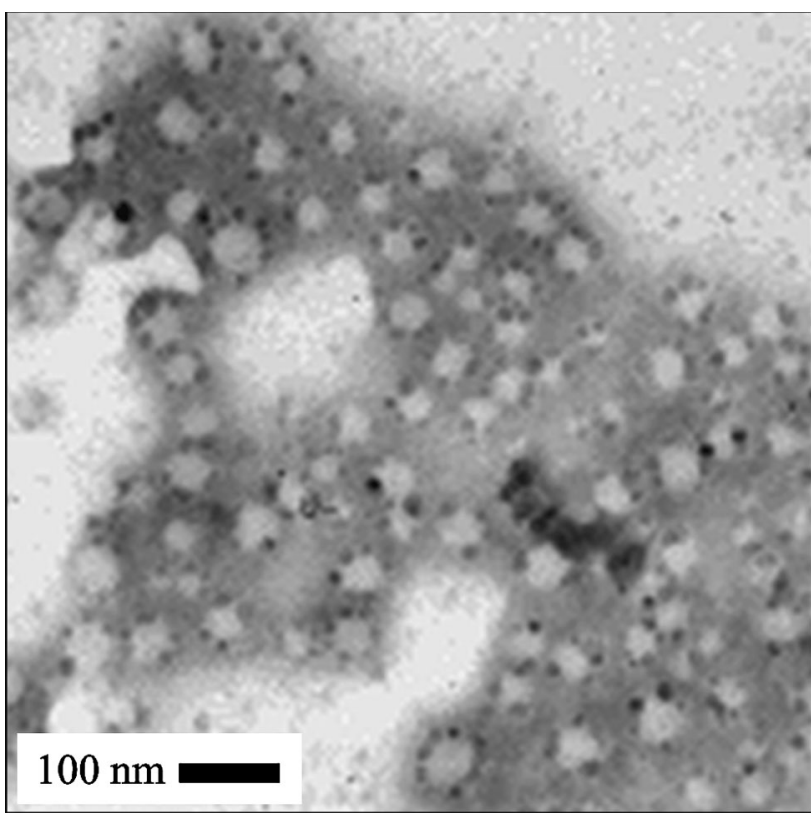

Fig. 7 TEM image of $\mathrm{MPC}_{100}-\mathrm{DPA}_{100}$ nanoparticle micelles displaying micelle diameters in the order of $50-80 \mathrm{~nm}$

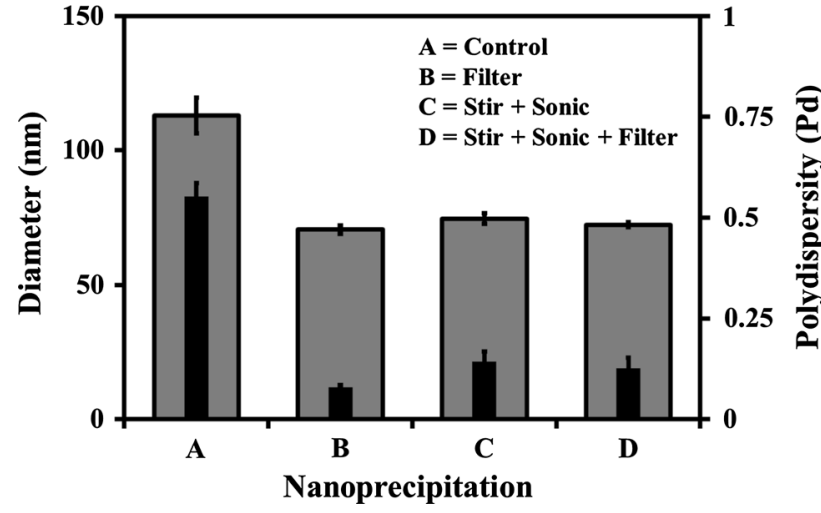

Fig. 8 Particle diameter (outer bar) and polydispersity (inner bar), measured with PCS $\left(25^{\circ} \mathrm{C}\right)$, of $\mathrm{MPC}_{100}-\mathrm{DPA}_{100}$ micelles, formed via nanoprecipitation from $\mathrm{MeOH}$ in $\mathrm{PBS}$ ( $\mathrm{pH}$ 7.4), illustrating the effect of filtration, stirring, and sonication on the $\mathrm{D}_{\mathrm{h}}$ and $\mathrm{Pd}$ (Mean $\pm \mathrm{SD}$, $\mathrm{n}=6)$

$(0.22 \mu \mathrm{m})$ the system after nanoprecipitation in order to reproducibly produce monodisperse systems ( $\mathrm{Pd}$ below 0.1 , thus removing the requirement for the previous stirring and sonication steps.

\subsection{Loading ratio of fluorescent probe}

In order to assess cellular uptake of the $\mathrm{MPC}_{100}-\mathrm{DPA}_{100}$ $\mathrm{MeOH}-\mathrm{PBS}$ system, the fluorescent dye Nile Red (NR) was loaded into the system. Figure 9 illustrates the effect that alterations in the polymer:dye ratio had on the $\mathrm{D}_{\mathrm{h}}$ and $\mathrm{Pd}$ of the system. It can be seen that at the w/w ratios of

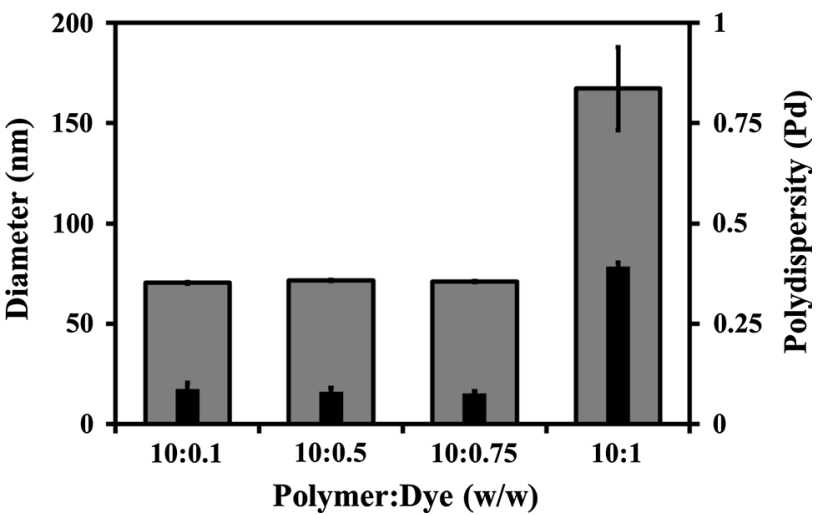

Fig. 9 Particle diameter (outer bar) and polydispersity (inner bar), measured with PCS $\left(25^{\circ} \mathrm{C}\right)$, of $\mathrm{MPC}_{100}-\mathrm{DPA}_{100}$ micelles, loaded with Nile Red, formed via nanoprecipitation from $\mathrm{MeOH}$ in $\mathrm{PBS}(\mathrm{pH}$ 7.4), illustrating the effect of alterations to the polymer:dye w/w loading ratio upon the $\mathrm{D}_{\mathrm{h}}$ and $\mathrm{Pd}$ (Mean $\pm \mathrm{SD}, \mathrm{n}=6$ )

10:0.1, 10:0.5, and 10:0.75 the system remained stable, with a $D_{h}$ of circa $70 \mathrm{~nm}$ and Pd below 0.1, indicating monodispersity. At the ratio of 10:1 the $D_{h}$ increased markedly to circa $167 \mathrm{~nm}$, with a Pd of circa 0.4 , suggesting the presence of a polydisperse system with larger, less well ordered, particle sizes.

\subsection{Cytotoxicity and cellular uptake}

The in vitro cytotoxicity of the $\mathrm{MPC}_{100}-\mathrm{DPA}_{100}$ micelles was investigated by comparing the cell colony formation numbers of the polymer micelle containing samples, with those of a polymer-free cell medium control plate. The data indicated that the micelles were essentially non-toxic at the tested concentrations, as seen in Fig. 10, and that the PBS and methanol controls also displayed similarly low levels of cellular toxicity at all but the highest concentration tested.

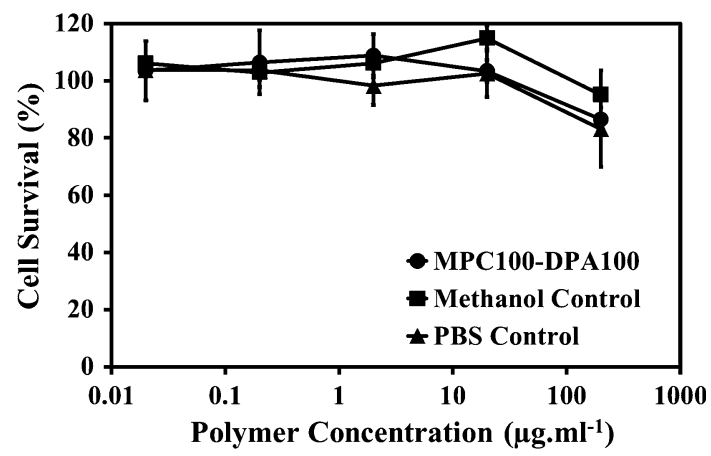

Fig. 10 The in vitro cytotoxicity of the $\mathrm{MPC}_{100}-\mathrm{DPA}_{100}$ micelles (MeOH-PBS system) tested on V79 cells. The percent survival of test sample cells was derived from comparison to cell medium only control wells. Samples were incubated for 5 days at $37{ }^{\circ} \mathrm{C}$ in $5 \%$ $\mathrm{CO}_{2}($ Mean $\pm \mathrm{SD}, \mathrm{n}=6)$ 
The cellular uptake of $\mathrm{MPC}_{100}-\mathrm{DPA}_{100}(\mathrm{MeOH}-\mathrm{PBS})$ micelles loaded with NR florescent dye was investigated using CLSM and V79 cells. A seen in Fig. 11 an apparent uptake of the NR loaded micelles was observed, as evidenced by the NR fluorescence (a), whilst the brightfield image (b) of the same field of view indicated that the cells had maintained a healthy morphology.

\section{Discussion}

Previous work has demonstrated that MPC-DPA copolymers molecularly dissolve in acidic solutions, form micelles when deprotonated in higher $\mathrm{pH}$ solutions, will dissociate when the $\mathrm{pH}$ is lowered again, and in doing so can be used to controllably load, deliver, and release hydrophobic compounds in vitro, whilst maintaining colloidal stability at physiological pH $[17,24]$. Upon cellular internalisation, via endocytosis [25], the micelles are exposed to a low $\mathrm{pH}$ environment [26] which brings about micelle dissociation and drug release. It is therefore hypothesised that MPC-DPA micelles could be further developed and optimised to provide efficacious systemic delivery of clinically relevant therapeutic compounds, for example anticancer drugs, with recent in vivo studies continuing to support this concept [22]. The MPC component of the copolymer offers biomimetic and non-thrombogenic properties $[15,27,28]$ which may provide the micelle corona with biocompatible performance in a similar manner to poly (ethylene glycol) (PEG) shielded Stealth liposomes [29], and thus in principle afford the MPC-DPA micelles a level of protection and defence against opsonisation induced RES clearance. Therefore the accurate and reproducible control of particle size, and polydispersity, is fundamental to effective biodistribution, and thus central to engineering long circulating MPC-DPA based NIDS, as particle size acutely influences RES clearance [1], particle accumulation at tumour sites via EPR [13, 14], and the rate and route of cellular internalisation via endocytosis [30]. Indeed, the poorly water soluble anti-cancer drugs tamoxifen and paclitaxel have been successfully loaded into other MPC-DPA based micelles [21, 24].

The principles of the nanoprecipitation method of micelle formation, also referred to as solvent displacement or solvent injection, have previously been employed to prepare a range of alternative nanoparticle systems [31-35] and was herein optimised for the polymer $\mathrm{MPC}_{100^{-}}$ $\mathrm{DPA}_{100}$. In this study nanoprecipitation proved to be an effective, rapid and straight forward micellisation technique, producing monodisperse micelle systems with mean diameters of circa $70 \mathrm{~nm}$ when using $\mathrm{MeOH}$ as the solvent and PBS as the non-solvent. This was a significant improvement over the previously employed $\mathrm{pH}$ titration method of MPC-DPA micelle formation which had produced smaller micelles with a higher level of polydispersity [17]. Interestingly, EtOH-based systems produced larger particles than the $\mathrm{MeOH}$ derived systems (Fig. 1), an effect which has also been reported for other nanoprecipitation based polymeric micelle systems exploring solvent selection [34, 35] and attributed to differing solubility of the polymers between solvents. PC based polymers have been reported to be soluble across the full range of methanol:water ratio mixes, whilst being less soluble in ethanol:water mixes, credited to the affinity of the PC headgroup to the alcohols relative to the water content, and the resultant co-nonsolvency effects [36, 37], which may

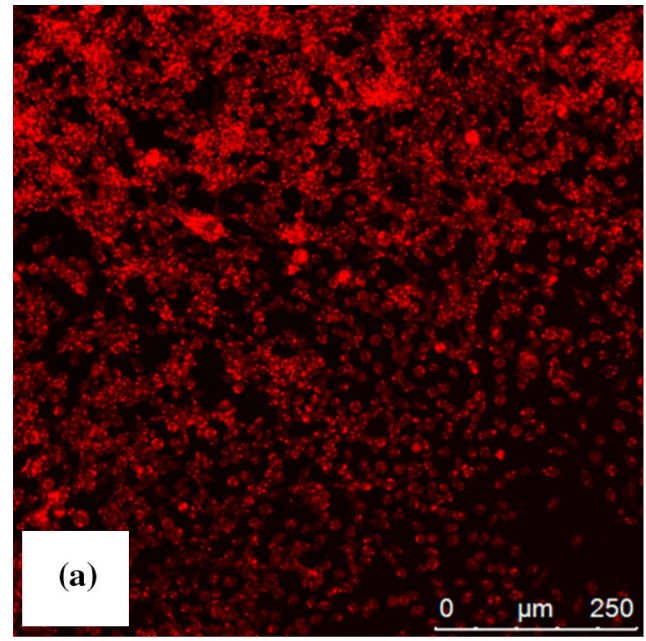

Fig. 11 Confocal laser scanning microscopy image of V79 cells incubated with NR loaded MPC $_{100}-\mathrm{DPA}_{100}$ micelles (MeOH-PBS system). Image a displays NR fluorescence, indicating apparent

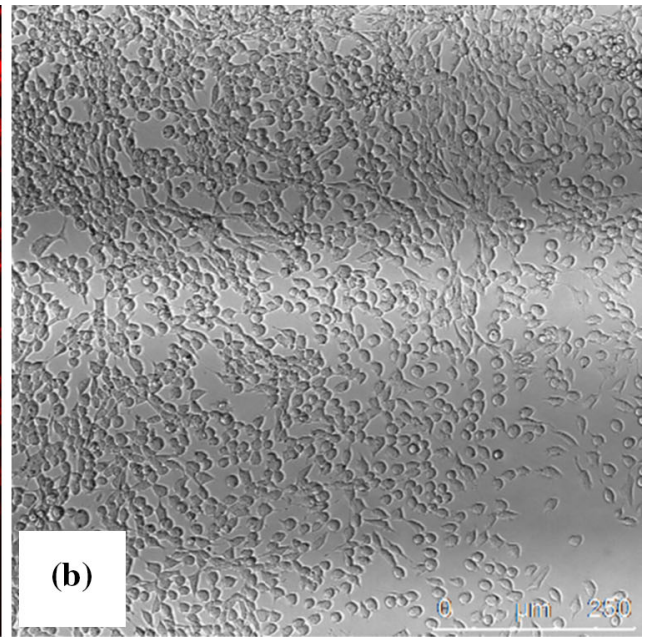

uptake of the NR loaded micelles, whilst image b provides brightfield evidence of healthy cell morphology 
account for the contrasting results observed in this work. Moreover, these findings were in good agreement with other work, that found the choice of solvent could influence particle size, and blends of solvents could be used to control particle size [34, 35, 38].

The maximum theoretical length of an $\mathrm{MPC}_{100}-\mathrm{DPA}_{100}$ unimer is $60 \mathrm{~nm}$ fully extended, based on a $0.15 \mathrm{~nm}$ carbon to carbon length, with each residue joined at a carbon bond and with one carbon $(0.15 \mathrm{~nm})$ between residues. However taking into account the $120^{\circ}$ carbon bond angle, the distance between each residue of the polymer would be $0.26 \mathrm{~nm}$, and therefore the unimer length would be $52 \mathrm{~nm}$. In micelle form if the aggregated unimers were unfolded and had no hydrophobic domain overlap, the maximum theoretical micelle diameter would be $104 \mathrm{~nm}$, herein the PCS measurements indicated the $\mathrm{MeOH}$ based particles were circa $70 \mathrm{~nm}$, and EtOH system particles were circa $128 \mathrm{~nm}$ in diameter. Therefore whilst the $\mathrm{MeOH}$ system particles fit the size profile for micelles, the EtOH systems exceeded the maximum theoretical micelle diameter, and would thus appear to be more complex structures, possibly wormlike micelles or vesicles, further TEM imaging would help resolve this. Additionally any residual EtOH and $\mathrm{MeOH}$ in the buffer, post-injection, may have affected the solubility of the polymer, and thus lead to the difference in particle size observed, however the subsequent exhaustive dialysis (Fig. 2), utilised to remove residual solvent, indicated this was unlikely to be the case, as particle size remained unchanged post-dialysis. However, it is clear that choice of solvent can affect the size, and possibly morphology of the MPC-DPA particles, as reported for other systems [34, 35, 38, 39].

The EtOH and $\mathrm{MeOH}$ based systems were reproducible in both PBS and McB (Fig. 3), with only a slight reduction in particle diameter for $\mathrm{MeOH}$ in $\mathrm{PBS}$ versus the $\mathrm{McB}$, but solution ionic strength is reported to influence micelle aggregation number, critical micelle concentration (CMC), and size [40, 41], however loading of the hydrophobic model compound OOT did not produce any discernable changes to the systems. Loading micelles with hydrophobic compounds can result in particle size changes [42-44] as has been seen in other MPC-DPA based micelle systems [24], however the previous micelle preparation method differed from that used for this study, which may account for apparent variance in particle size and stability. In contrast the $\mathrm{MPC}_{100}-\mathrm{DPA}_{100}$ systems were principally stable for both hydrophobic model compounds loaded, (Figs. 3, 9), until a 10:1 (w/w) polymer:dye ratio was reached (Fig. 9).

Polymeric micelle systems often possess very low CMC values and display good resistance to dissociation [2, 3]. The results of this study indicated that the $\mathrm{MPC}_{100}-\mathrm{DPA}_{100}$ micelles were highly resistant to dilution induced micelle dissociation, which is a major challenge for systemically administered self-assembling NIDS to overcome. The $\mathrm{MPC}_{100}-\mathrm{DPA}_{100}$ micelles were detectable, using PCS, down to polymer concentrations of 3.125 and $0.625 \mathrm{mg} \mathrm{l}^{-1}$ for $\mathrm{MeOH}$ and $\mathrm{EtOH}$ respectively in PBS, which were 10and 100-fold improvements over the previous $\mathrm{pH}$ titration system CMC for the polymer [17]. The dilution stability values determined (Fig. 4) were also comparable to CMC values published for other MPC-DPA micelle systems, ranging from 4 to $25 \mathrm{mg} \mathrm{l}^{-1}[45,46]$ as well as other copolymers containing either MPC or DPA ranging from 3.1 to $43 \mathrm{mg} \mathrm{l}^{-1}[47,48]$. Indeed it is possible that the micelle systems employed in this study would persist at lower polymer concentrations, as polymeric micelles have been found to have very low CMC values combined with high particle stability and slow particle dissociation [2,3]; however the limit of detection for the PCS measurement was reached. Further study utilising pyrene solubilisation [36] would help elucidate this.

Temperature and time stability of candidate NIDS is of great importance if they are to be medically developed, as both thermal robustness and long term colloidal stability will influence the storage and handling requirements of the systems, and thus their ease of use in a full range of clinical settings. The $\mathrm{MPC}_{100}-\mathrm{DPA}_{100}$ micelle systems displayed good thermal stability, with no critical micelle temperature (CMT) or cloud points observed across a wide temperature range (Fig. 5), which was in contrast to other MPC-DPA micelle systems [49] which were reported to vary in particle diameter as temperature changed, possibly due to thermally induced micelle phase transitions [50], but again the micelle preparation method differed from that used for this study, as did the MPC-DPA block lengths, which may account for this variance. The thermal stability (Fig. 5), together with the stability over time observed (Fig. 1) indicate the $\mathrm{MPC}_{100}-\mathrm{DPA}_{100}$ systems have the potential to be adaptable to a range of storage and transport options.

In this current study the particle size for the $\mathrm{MeOH}$ based system indicated from the AFM imaging (Fig. 6) was in close agreement with the mean diameter (circa $70 \mathrm{~nm}$ ) measured using PCS (Fig. 3), as was the TEM imaging result (Fig. 7). These TEM results were similar to reported diameters determined by TEM for other MPCDPA micelles [24, 45, 46] but noting these systems were of different MPC-DPA block length ratios, and not prepared by using the nanoprecipitation method developed in this study. The negative staining technique used for the TEM imaging was an established method [3, 51, 52] and the resultant TEM image (Fig. 7) was comparable to other published negatively stained micelle TEM images, likewise the AFM image (Fig. 6) was also similar to other micelle system AFM images [53]. With regard to the wider particle diameter size range observed by TEM and AFM, compared 
to PCS, the micelles were fully hydrated and in an aqueous solution for PCS analysis, however during AFM and TEM sample preparation it is not unusual for micelles to spread, flatten, shrink, or contract during staining and drying, as they are not solid particles.

In order to optimise nanoprecipitation for the MPCDPA micelles prepared from $\mathrm{MeOH}-\mathrm{PBS}$, the effect of stirring, sonication, and filtration upon the micelle solutions was examined (Fig. 8), all of which are commonly used methods published for micelle formation, and more so in the formation of polymersomes [20, 54, 55]. It was found in this case that there was no benefit observed from the stirring or sonication of the $\mathrm{MPC}_{100}-\mathrm{DPA}_{100}$ micelles, indeed it was found that sonication increased the polydispersity of the systems, possibly due to disruption of the micelles into a wider average diameter range, and that filtration was the only post-precipitation step required to achieve good monodispersity. The filtration step may have been acting as an extrusion process to induce the observed uniformity in the systems, as extrusion is one of a number of steps required to obtain uniform MPC-DPA and other polymersomes $[54,55]$. In terms of further development, it has been reported that increasing the volume of solvent used for nanoprecipitation will increase the number or concentration of micelles in the solution, whilst increasing the polymer concentration will increase particle size [34, 35], which together with the solvent effects observed in this study, provides a large scope for further investigation.

The results from the in vitro cytotoxity assay (Fig. 10) indicated that the $\mathrm{MPC}_{100}-\mathrm{DPA}_{100}$ polymer was of very low cellular toxicity, which was in good agreement with other MPC-DPA polymers tested [17, 21, 56]. The small reduction in cell survival observed at $200 \mu \mathrm{g} \mathrm{ml}^{-1}$ polymer concentration was possibly due to the $50 \%$ dilution of cell medium at the initial dilution step causing cell stress or reduced cell growth, rather than presence of the polymer, as the PBS control also displayed similar results. Similarly the $\mathrm{MeOH}$ used in sample preparation, and control volumes tested, also did not present any evidence of cellular toxicity over the PBS control. The V79 fibroblast cells may internalise nanoparticles via endocytosis [30], and an apparent uptake of the $\mathrm{MPC}_{100}-\mathrm{DPA}_{100}$ micelles was observed here using CLSM (Fig. 11a), with brightfield data (Fig. 11b) also displaying healthy cell morphology after exposure to the polymer, as further evidence of low cellular toxicity. Indeed a wide range of cell types have been exposed to $\mathrm{MPC}_{25}-\mathrm{DPA}_{70}$ polymersomes [54], none of which displayed any significant signs of toxicity, and thus the $\mathrm{MPC}_{100}-\mathrm{DPA}_{100}$ micelles should also be biocompatible. Whilst the existing MPC-DPA polymersome systems have a number of benefits, most notably the ability to deliver both hydrophobic and hydrophilic compounds [19, 20, 54, 56], the sample preparation required to attain the desired particle size and polydispersity is complex, whilst in contrast, these $\mathrm{MPC}_{100}-\mathrm{DPA}_{100}$ micelles offer the prospect of easily prepared reproducible monodisperse micelle systems, with the potential to deliver a wide range of poorly water soluble compounds.

Despite the small volume of $\mathrm{MeOH}$ used during the nanoprecipitation process, the potential toxicity of $\mathrm{MeOH}$ [57] cannot be ignored, and as such $\mathrm{MeOH}$ is often excluded from studies due to its inherent Class 3 toxicity rating [34]. However the results of this study are very promising in terms of controllable micelle system characteristics and properties, and this positive data warrants further investigation into methods to achieve and confirm removal of the $\mathrm{MeOH}$. Moreover, given the cell assay data (Fig. 10) indicated that there was no residual toxicity from the $\mathrm{MeOH}$ used to prepare the micelles, it may be the case that $\mathrm{MeOH}$ dissipates from the system at ambient temperature. Additionally, given the boiling point of $\mathrm{MeOH}$ is approximately $65^{\circ} \mathrm{C}$, there was no evidence of micelle system shifts or alterations at $70{ }^{\circ} \mathrm{C}$ during PCS temperature scans (Fig. 5). The toxicity of the $\mathrm{MeOH}$ should also be taken into context of the application and the desired effect, for instance in the case of anti-cancer drug delivery, agents such as paclitaxel and doxorubicin are inherently toxic themselves, thus further investigation into understanding $\mathrm{MeOH}$ tolerance levels could be warranted, given low levels of unaccounted $\mathrm{MeOH}$ exposure occurs via environmental and dietary exposure. Indeed many pharmaceutical and medicinal compounds have serious side effects and wider health implications, but the benefit of treatment is perceived to outweigh these.

The $\mathrm{MPC}_{100}-\mathrm{DPA}_{100}$ diblock copolymer investigated in this study is essentially surfactant like, in that it is comprised of hydrophobic and hydrophilic domains, and in theory at a concentration above the CMC the unimeric polymer chains would to aggregate together to form micelles, with the hydrophobic blocks forming the core of the micelles [58]. The micellisation process is an example of the hydrophobic effect [59], where non-polar molecules or non-polar parts of molecules are spontaneously removed from water [60]. The primary driving force of this being the large energy required to form a cavity in the water to accommodate the hydrophobe, which is thermodynamically unfavourable and thus decreases the solubility of the hydrophobic molecules and favours micellisation [61]. The large energy is required because of the high cohesion of water molecules resulting from the high hydrogen bonding density [60]. The hydrophobic effect thus provides the driving force for the aggregation of the hydrophobic polymer domains, whilst electrostatic repulsion between the polar, water soluble, hydrophilic domains or head groups can control the shape and size the micelles [62]. Thus, in reality the shape of micelle based systems is 
controlled by the balance between these attractive hydrophobic and repulsive electrostatic forces [63]. The hydrophobic force will try to minimise the surface area to avoid water contact, whilst the repulsive force will try to maximise the surface area to keep the polar domains as far apart as possible [64]. This can ultimately lead to the spontaneous curvature of micelle formation, as the curvature allows a greater spacing between the polar domains than a planar bilayer [65]. In terms of drug loading, when a drug is mixed with micelles or surfactant molecules they may interact as a result of the hydrophobic effect and also electrostatic effects [66]. Drugs with no significant hydrophobic surface area may interact with the micelles or surfactants as a result of electrostatic effects arising from the charge associated with the drug and surfactant molecules. For drugs or hydrophobic compounds with a large hydrophobic surface area the hydrophobic effect will drive their interaction [66], although other chemical interactions may also occur, such a dipole interactions and hydrogen bonding depending on the chemical structure of the drug or surfactant [67]. The result of this hydrophobic effect is that poorly water soluble hydrophobic compounds, for example OOT and NR, will preferentially partition into the hydrophobic domain of the micelle core and undergo hydrophobic interactions [68].

Whilst the NR fluorescent probe employed in this study was hydrophobic, negligibly water soluble, and thus should preferentially partition into the core [68] of the $\mathrm{MPC}_{100^{-}}$ $\mathrm{DPA}_{100}$ micelles due to the hydrophobic effect [59-61], there is evidence from other MPC-DPA based micelle systems loaded with hydrophobic compounds, that a slow diffusion based release of the hydrophobic load at $\mathrm{pH} 7.4$ can occur [24, 45]. However it should be noted that the studies $[24,45]$ were based on an excess volume dialysis model, rather than a fixed small volume and concentration system reflective of a tissue culture well. Given that micelles are generally considered to be thermodynamically stable above their CMC [45, 58], and noting that the polymer concentration utilised for the CLSM assay was $200 \mu \mathrm{g} \mathrm{ml}^{-1}$, with Fig. 4 indicating micelle stability at that concentration, it suggests that the $\mathrm{MPC}_{100}-\mathrm{DPA}_{100} \mathrm{mi}-$ celles would persist at the concentration tested. Additionally, as the presence of hydrophobic compounds can enhance micelle stability [44], and the time data from this current study (Fig. 1) further suggested excellent colloidal stability, any micelle dissociation and NR release should therefore be minimal during the CLSM in vitro cell uptake assay.

However, the possibility remains that NR may have slowly diffused from the micelles during the assay incubation period, resulting in the cellular staining observed (Fig. 11). But, given the apparently rapid uptake of other MPC-DPA based systems [56], some of the NR loaded micelles may have undergone endocytosis into the cells and contributed to the fluorescence observed. As such, further study of the system with higher resolution microscopy would help elucidate this, as NR released in solution would be expected to primarily stain the lipid containing outer cell membrane, whereas micelle loaded NR should undergo cellular internalisation via endocytosis $[21,30,56]$, and potentially enhance the level of fluorescent staining achieved [54]. Moreover, this could be further explored by preparing fluorescent dye labelled MPC-DPA [20], which would facilitate the investigation of both the fate of the micelle upon internalisation, and an additional second fluorescent dye loaded into micelle, and thus identify any co-localisation of the micelle and loaded dye.

Whilst the $\mathrm{MeOH}$ derived systems investigated here appeared to form surfactant-like spherical micelle structures, the larger particle diameter of the EtOH based systems suggests they may have formed more complex structures. It has been suggested for MPC-DPA polymers that when the DPA block length reaches approximately twice that of MPC block, then vesicle like polymersomes will form rather than micelles [49], indeed $140 \mathrm{~nm}$ diameter $\mathrm{MPC}_{25}-\mathrm{DPA}_{120}$ based vesicle-like particles have been reported [19] and a range of other polymersomes sizes greater than $100 \mathrm{~nm}$ diameter have been reported for $\mathrm{MPC}_{25}-\mathrm{DPA}_{70}[20,54,56]$ however in this instance, given the equal block length $\mathrm{MPC}_{100}-\mathrm{DPA}_{100}$ polymer, it would therefore be expected that micelles would be the predominate structure assembled.

The transition from spherical micelles to vesicles or polymersomes involves intermediate structures in the form of cylindrical or wormlike micelles [69] with solvent selectivity, block length and ratio [70], temperature, and the presence of salts and additives bringing about the transition of $\mathrm{AB}$ diblock copolymers from spherical micelles to a cylindrical or wormlike morphology [71, 72]. It is possible for rod or cylinder-like morphologies to further aggregate and form curved, bowl-shaped structures which can close over to form vesicles [73]. Therefore, given that the MPCDPA polymer used for this study were also $A B$ diblock copolymers it is possible that they may also have undergone transformation from spherical micelles to a cylinder or wormlike morphology and possibly through to vesicle formation, which may therefore account for the larger particle size seen for the EtOH based systems.

The principle concept for these MPC-DPA micelle systems, is that they are dynamic and controllable, and given the correct polymer, system conditions, and preparation parameters, have the potential to form a large number of organised structures [49] including spherical micelles, wormlike cylindrical micelles, and vesicles, all of which presents substantial scope for further investigation and research. 


\section{Conclusions}

In conclusion, progressing from work published previously on MPC-DPA micelles [17, 24] these results suggest that the MPC-DPA diblock copolymers continue to offer the potential for the development of long circulating stimuli responsive micelle NIDS. The reproducible monodisperse nature of the $\mathrm{MPC}_{100}-\mathrm{DPA}_{100}$ micelles, together with the demonstrated thermal and dilution stability, lends itself to the possibility that further designer micelles could be engineered to very specific diameters by alteration of the MPC and DPA block lengths. Indeed it has been suggested that the ratio between MPC and DPA is critical for the size and morphology of the particles formed [49], and as such developing accurate control of particle size and polydispersity is inherent to optimising control of NIDS biodistribution.

This paper has described for the first time the development and optimisation of a novel preparation process, utilising nanoprecipitation, for monodisperse MPC-DPA micelle nanoparticle systems. These nanoparticles possess key biomimetic and $\mathrm{pH}$ responsive properties [17, 24] required for development of in vivo applications. OOT and NR were employed as model therapeutic compounds to test the systems, resulting in the successful formation of stable monodisperse micelles, with an apparent in vitro cellular delivery of these being demonstrated. These encouraging results highlight the continued potential for MPC-DPA systems to be utilised for a variety of intracellular delivery applications, for example anticancer, antimicrobial, and diagnostic imaging, harnessing the hydrophobic nature of many therapeutics to overcome their intrinsically low water solubility.

Acknowledgments The authors gratefully acknowledge the Biotechnology and Biological Sciences Research Council (BBSRC) for the joint research Grant to support this project (85/E11449 and 107/E11449). We also thank Prof Steven Armes (University of Sheffield, UK) for supply of the test polymer, and Biocompatibles UK Ltd for the provision of materials and financial support for JPS.

Open Access This article is distributed under the terms of the Creative Commons Attribution License which permits any use, distribution, and reproduction in any medium, provided the original author(s) and the source are credited.

\section{References}

1. Singh R, Lillard JW. Nanoparticle-based targeted drug delivery. Exp Mol Pathol. 2009;86(3):215-23.

2. Kataoka K, Matsumoto T, Yokoyama M, Okano T, Sakurai Y, Fukushima S, Okamoto K, Kwon GS. Doxorubicin-loaded poly(ethylene glycol)-poly(b-benzyl-L-aspartate) copolymer micelles: their pharmaceutical characteristics and biological significance. J Control Release. 2000;64:143-53.

3. Lavasanifar A, Samuel J, Kwon GS. Micelles of poly(ethylene oxide)-block-poly( $\mathrm{N}$-alkyl stearate L-aspartamide): synthetic analogues of liposomes for drug delivery. J Biomed Mater Res. 2000;52(4):831-5.

4. Gref R, Yoshiharu M, Peracchia MT, Trubetskoy V, Torchilin V, Langer R. Biodegradable long-circulating polymeric nanospheres. Science. 1994;263(18):1600-3.

5. Passirani C, Barratt G, Devissaguet JP, Labarre D. Long-circulating nanoparticles bearing heparin or dextran covalently bound to poly(methyl methacrylate). Pharm Res. 1998;15(7):1046-50.

6. Porter CJ, Davies MC, Davis SS, Illum L. Microparticulate systems for site-specific therapy: bone marrow targeting. In: Domb AJ, editor. Polymeric site-specific pharmacotherapy. Chichester: Wiley; 1994. p. 158-203.

7. Strand SE, Andersson L, Bergqvist L. Applications and characterization of radiolabeled or magnetizable nano- and microparticulates for RES, lymph, and blood flow studies. In: Rembaum A, Tökés ZA, editors. Microspheres: medical and biological applications. Florida: CRC Press; 1988. p. 193-227.

8. Tabata Y, Ikada Y. Effect of the size and surface charge of polymer microspheres on their phagocytosis by macrophage. Biomaterials. 1988;9:356-62.

9. Stolnik S, Illum L, Davis SS. Long circulating microparticulate drug carriers. Adv Drug Deliv Rev. 1995;16:195-214.

10. Yoo HS, Park TG. Biodegradable polymeric micelles composed of doxorubicin conjugated PLGA-PEG block copolymer. J Control Release. 2001;70:63-70.

11. Moghimi SM, Hunter AC, Murray JC. Long-circulating and targetspecific nanoparticles: theory to practice. Pharmacol Rev. 2001;53(2):283-318.

12. Moghimi SM, Gray T. A single dose of intravenously injected poloxaminecoated long-circulating particles triggers macrophage clearance of subsequent doses in rats. Clin Sci. 1997;93:371-9.

13. Takakura Y, Mahato RI, Hashida M. Extravasation of macromolecules. Adv Drug Deliv Rev. 1998;34:93-108.

14. Maeda $\mathrm{H}$. The enhanced permeability and retention (EPR) effect in tumor vasculature: the key role of tumor-selective macromolecular drug targeting. Adv Enzyme Regul. 2001;41:189-207.

15. Lewis AL. Phosphorylcholine-based polymers and their use in the prevention of Biofouling. Colloids Surf B. 2000;18:261-75.

16. Hayward JA, Chapman D. Biomembrane surfaces as models for polymer design: the potential for haemocompatibility. Biomaterials. 1984;5:135-42.

17. Salvage JP, Rose SF, Phillips GJ, Hanlon GW, Lloyd AW, Ma IY, Armes SP, Billingham NC, Lewis AL. Novel biocompatible phosphorylcholine-based self-assembled nanoparticles for drug delivery. J Control Release. 2005;104:259-70.

18. Ma IY, Tang Y, Billingham NC, Armes SP, Lewis AL, Lloyd AW, Salvage JP. Well-defined biocompatible block copolymers via atom transfer radical polymerisation of 2-methacryloyloxyethyl phosphorylcholine in protic media. Macromolecules. 2003;36:3475-84.

19. Du J, Tang Y, Lewis AL, Armes SP. pH-sensitive vesicles based on a biocompatible zwitterionic diblock copolymer. J Am Chem Soc. 2005;127:17982-3.

20. Colley HE, Hearnden V, Milagros AO, Cecchin D, Canton I, Madsen J, MacNeil S, Warren N, Hu K, McKeating JA, Armes SP, Murdoch C, Thornhill MH, Battaglia G. Polymersome-mediated delivery of combination anticancer therapy to head and neck cancer cells: 2D and 3D in vitro evaluation. Mol Pharm. 2014;11(4):1176-88.

21. Licciardi M, Craparo EF, Giammona G, Armes SP, Tang Y, Lewis AL. In vitro biological evaluation of folate-functionalised block copolymer micelles for selective anti-cancer drug delivery. Macromol Biosci. 2008;8(7):615-26.

22. Yu H, Yonglong Z, Lei J, Qi Y, Xinyu H, Lingli C, Zhiwen Z, Wangwen G, Yaping L. Induction of apoptosis in non-small cell lung cancer by down regulation of MDM2 using $\mathrm{pH}$-responsive 
PMPC-b-PDPA/siRNA complex nanoparticles. Biomaterials. 2013;34:2738-47.

23. Tsuchiya T. Studies on the standardisation of cytotoxicity tests and new standard reference materials useful for evaluating the safety of biomaterials. J Biomater Appl. 1994;9:138-57.

24. Licciardi M, Giammona G, Du J, Armes SP, Tang Y, Lewis AL. New folate-functionalised biocompatible block copolymer micelles as potential anti-cancer drug delivery systems. Polymer. 2006;47:2946-55.

25. Sharma A, Sharma US. Liposomes in drug delivery: progress and limitations. Int J Pharm. 1997;154:123-40.

26. Needham D, Dewhirst MW. The development and testing of a temperature sensitive drug delivery system for the treatment of solid tumors. Adv Drug Deliv Rev. 2001;53:285-305.

27. Zhang SF, Rolfe P, Wright G, Lian W, Milling AJ, Tanaka S, Ishihara K. Physical and biological properties of compound membranes incorporating a copolymer with a phosphorylcholine head group. Biomaterials. 1998;19:691-700.

28. Iwasaki Y, Sawada SI, Nakabayashi N, Khang G, Lee HB, Ishihara $\mathrm{K}$. The effect of the chemical structure of the phospholipid polymer on fibronectin adsorption and fibroblast adhesion on the gradient phospholipid surface. Biomaterials. 1990;20:2185-91.

29. Torchilin VP, Trubetskoy VS. Which polymers can make nanoparticulate drug carriers long-circulating. Adv Drug Deliv Rev. 1995;16:141-55.

30. Canton I, Battaglia G. Endocytosis at the nanoscale. Chem Soc Rev. 2012;41:2718-39.

31. Govender T, Stolnik S, Garnett MC, Illum L, Davis SD. PLGA nonparticles prepared by nanoprecipitation: drug loading and release studies of a water soluble drug. J Control Release. 1999;57:171-85.

32. Quintanar-Guerrero D, Allémann E, Fessi H, Doelker E. Preparation techniques and mechanisms of formation of biodegradable nanoparticles from preformed polymers. Drug Dev Ind Pharm. 1998;24(12):1113-28.

33. Fessi H, Puisieux F, Devissaguet JP, Ammoury N, Benita S. Nanocapsule formation by interfacial polymer deposition following solvent displacement. Int J Pharm. 1989;55:R1-4.

34. Bilati U, Allemann E, Doelker E. Development of a nanoprecipitation method intended for the entrapment of hydrophilic drugs into nanoparticles. Eur J Pharm Sci. 2005;24:67-75.

35. Schubert MA, Muller-Goymann CC. Solvent injection as a new approach for manufacturing lipid nanoparticles: evaluation of the method and process parameters. Eur J Pharm Biopharm. 2003;55:125-31.

36. Lewis AL, Hughes PD, Kirkwood LC, Leppard SW, Redman RP, Tolhurst LA, Stratford PW. Synthesis and characterisation of phosphorylcholine based polymers useful for coating blood filtration devices. Biomaterials. 2000;21:1847-59.

37. Edmondson S, Nguyen NT, Lewis AL, Armes SP. Co-nonsolvency effects for surface-initiated poly(2-(methacryloyloxy)ethyl phosphorylcholine) brushes in alcohol/water mixtures. Langmuir. 2010;26(10):7216-26.

38. Kohori F, Yokoyama M, Sakai K, Okano T. Process design for efficient and controlled drug incorporation into polymeric micelle carrier systems. J Control Release. 2002;78:155-63.

39. Alexandridis P, Spontak RJ. Solvent-regulated ordering in block copolymers. Curr Opin Colloid Interface Sci. 1999;4:130-9.

40. Dubin PL, Principi JM, Smith BA, Fallon MA. Influence of ionic strength and composition on the size of mixed micelles of sodium dodecyl sulfate and Triton X-100. J Colloid Interface Sci. 1989;127(2):558-65.

41. Wang R, Li Y, Song Y, Zhi L. Effects of $\mathrm{pH}$, temperature and ionic strength on aggregation behavior of dodecyldiethoxylamine oxide. J Surfactants Deterg. 2014;17(2):223-9.
42. Oranli L, Bahadur P, Riess G. Hydrodynamic studies on micellar solutions of styrene-butadiene block copolymers in selective solvents. Can J Chem. 1984;63:2691-6.

43. Govender T, Stolnik S, Xiong C, Zhang S, Illum L, Davis S. Drug polyionic block copolymer interactions for micelle formation: physicochemical characterisation. J Control Release. 2001;75:249-58.

44. Sharma PK, Reilly MJ, Jones DN, Robinson PM, Bhatia SR. The effect of pharmaceuticals on the nanoscale structure of PEOPPO-PEO micelles. Colloids Surf B. 2008;61:53-60.

45. Giacomelli C, Le Men L, Borsali R, Lai-Kee-Him J, Brisson A, Armes SP, Lewis AL. Phosphorylcholine-based $\mathrm{pH}$-responsive diblock copolymer micelles as drug delivery vehicles: light scattering, electron microscopy, and fluorescence experiments. Biomacromolecules. 2006;7:817-28.

46. Licciardi M, Tang Y, Billingham NC, Armes SP, Lewis AL. Synthesis of novel folic acid-functionalized biocompatible block copolymers by atom transfer radical polymerization for gene delivery and encapsulation of hydrophobic drugs. Biomacromolecules. 2005;6:1085-96.

47. Dayananda K, Kim MS, Kim BS, Lee DS. Synthesis and characterisation of MPEG-b-PDPA amphiphilic block copolymer via atom transfer radical polymerisation and its $\mathrm{pH}$-dependant micellar behaviour. Macromol Res. 2007;15(4):385-91.

48. Chu H, Liu N, Wang X, Jiao Z, Chen Z. Morphology and in vitro release kinetics of drug-loaded micelles based on well-defined PMPC-b-PBMA copolymer. Int J Pharm. 2009;371:190-6.

49. Pearson RT, Warren NJ, Lewis AL, Armes SP, Battaglia G. Effects of $\mathrm{pH}$ and temperature on PMPC-PDPA copolymer selfassembly. Macromolecules. 2013;46:1400-7.

50. Huang YY, Chen HL, Hashimoto T. Face-centered cubic lattice of spherical micelles in block copolymer/homopolymer blends. Macromolecules. 2003;36(3):764-70.

51. Ouchi T, Miyazaki H, Arimura H, Tasaka F, Hamada A, Ohya Y. Formation of polymeric micelles with amino surfaces from amphiphilic AB-type diblock copolymers composed of poly(glycolic acid lysine) segments and polylactide segments. J Polym Sci Part A. $2002 ; 40(10): 1426-32$.

52. Lavasanifar A, Samuel J, Kwon GS. Micelles self-assembled from poly(ethylene oxide)-block-poly(N-hexyl stearate L-aspartamide) by a solvent evaporation method: effect on the solubilization and haemolytic activity of amphotericin B. J Control Release. 2001;77:155-60.

53. Xu JP, Ji J, Chen WD, Shen JC. Novel biomimetic surfactant: synthesis and micellar characteristics. Macromol Biosci. 2005;5:164-71.

54. Massignani M, Canton I, Sun T, Hearnden V, MaCNeil S, Blanazs A, Armes SP, Lewis A, Battaglia G. Enhanced fluorescence imaging of live cells by effective cytosolic delivery of probes. PLoS ONE. 2010;5(5):e10459. doi:10.1371/journal.pone.0010459.

55. Brinkhuis RP, Graaf F, Hansen MB, Visser TR, Rutjes FPJT, van Hest CJM. Dynamically functionalised polymersomes via hydrazine exchange. Polym Chem. 2013;4:1345-50.

56. Lomas H, Massignani M, Abdullah KA, Canton I, Lo Presti C, MacNeil S, Du J, Blanazs A, Madsen J, Armes SP, Lewis AL, Battaglia G. Non-cytotoxic polymer vesicles for rapid and efficient intracellular delivery. Faraday Discuss. 2008;139:143-59.

57. Tephly TR. The toxicity of methanol. Life Sci. 1991;48(11):1031-41.

58. Attwood D, Florence AT. Surfactant systems. Their chemistry, pharmacy, and biology. 1st ed. London: Chapman and Hall Ltd; 1983.

59. Schwarz US. Phase behaviour of amphiphilic systems. Acta Phys Pol B. 1998;29(6):1815-25.

60. Kronberg B, Castas M, Silvestoni R. Thermodynamics of the hydrophobic effect in surfactant solutions: micellization and adsorption. Pure Appl Chem. 1995;67(6):897-902. 
61. Kronberg B, Castas M, Silvestoni R. Understanding the hydrophobic effect. J Dispers Sci Technol. 1994;15(3):333-51.

62. Joshi JV, Aswal VK, Bahadur P, Goyal PS. Role of the counterion of the surfactant molecule on the micellar structure in aqueous solution. Curr Sci. 2002;83(1):47-9.

63. Ljosland E, Blokhus AM, Veggeland K, Backlund S, Hoiland H. Shape transitions in aqueous micellar systems as a function of pressure and temperature. In: Lindman B, Olofsson G, Stenius P, editors. Surfactants, adsorption, surface spectroscopy and disperse systems (Progress in Colloid and Polymer Science). Berlin: Springer-Verlag; 1985 . p. 34-7.

64. Tanford C. Thermodynamics of micelle formation: prediction of micelle size and size distribution. Proc Natl Acad Sci USA. 1974;71(5):1811-5.

65. Fattal DR, Andelamn D, Ben-Shaul A. The vesicle-micelle transition in mixed lipid-surfactant systems: a molecular model. Langmuir. 1995;11:1154-61.

66. Khossravi D. Drug-surfactant interactions: effect on transport properties. Int J Pharm. 1997;155(2):179-90.

67. Mrestani Y, Neubert RHH. Non-ionic micellar affinity capillary electrophoresis for analysis of interactions between micelles and drugs. J Pharm Biomed Anal. 2001;24:637-43.
68. Marzio LD, Marianecci C, Cinque B, Nazzarri M, Cimini AM, Cristiano L, Cifone MG, Alhaique F, Carafa M. pH-sensitive non-phospholipid vesicle and macrophage-like cells: binding, uptake and endocytotic pathway. Biochim Biophys Acta. 2008;1178:2749-56.

69. Levine DH, Ghoroghchian PP, Freudenberg J, Zhang G, Therien MJ, Greene MI, Hammer DA, Murali R. Polymersomes: a new multi-functional tool for cancer diagnosis and therapy. Methods. 2008;46:25-32.

70. Ahmed T, Aramaki K. Wormlike micelles in poly(oxyethylene) surfactant solution: growth control through hydrophilic-group size variation. J Colloid Interface Sci. 2008;327:180-5.

71. Termonia Y. Sphere-to-cylinder transition in dilute solutions of diblock copolymers. J Polym Sci Part B. 2002;40(9):890-5.

72. Acharya DP, Kunieda $H$. Wormlike micelles in mixed surfactant solutions. Adv Colloid Interface Sci. 2006;123:401-13.

73. Burke S, Shen H, Eisenberg A. Multiple vesicular morphologies from block copolymers in solution. Macromol Symp. 2001;175:273-83. 